\title{
Journal of

\section{A new method to synthesize very active and stable supported metal Pt catalysts: thermo-destabilization of microemulsions $\uparrow$}

\author{
Riny Y. Parapat, ${ }^{* a}$ Veronica Parwoto, ${ }^{a}$ Michael Schwarze, ${ }^{a}$ Bingsen Zhang, ${ }^{b}$ Dang Sheng Su ${ }^{b}$ \\ and Reinhard Schomäcker $* a$
}

\author{
Received 26th October 2011, Accepted 30th March 2012 \\ DOI: $10.1039 / \mathrm{c} 2 \mathrm{jm} 15468 \mathrm{~d}$
}

\begin{abstract}
A new technique to deposit nanoparticles synthesized in reverse micellar microemulsions onto support material without agglomeration is named thermal destabilization of microemulsion. The multifaceted Pt crystals, mostly truncated octahedra, were produced inside reverse micelles with an average size of $2.5 \mathrm{~nm}$ and a narrow size distribution. After deposition, the Pt crystals were found to be well dispersed on the support with an average size of $2.5 \mathrm{~nm}$. After testing with hydrogenation of $\alpha$-methyl styrene, the produced Pt-catalyst showed higher activity (6 times higher) and stability than commercial ones. The advantages of this synthesis route of nanoparticles include simple operation, and the ease of controlling the size and shape of nanoparticles without using capping agents.
\end{abstract}

\section{Introduction}

Efforts to increase the activity of catalytic nanoparticles are no longer focused only on reducing their size. Because nanoparticles with the same size but different shapes perform differently, many researchers are trying to control the shapes of nanoparticles. ${ }^{1}$ New strategies have been developed to produce multifaceted crystals. These are very active because the more faces the crystals have, the higher the concentration of atomic steps and edges that are readily available to participate in chemical reactions.

During the last decade, there has been a lot of interest in the synthesis of platinum nanoparticles of different shapes such as tetrahedral, cubic, nanowire, tetrapod, etc. ${ }^{1}$ Although many have successfully been produced with different shapes, they still remain in the colloidal state which can only be stable for a limited time. To create more stable catalysts, nanoparticles have been deposited on a support material. In general, it is difficult to preserve the size and shape of nanoparticles during the deposition process. This is a major challenge when preparing supported catalysts by deposition. Furthermore, one also has to consider the dispersion of nanoparticles on the support because it affects the catalyst performance.

Conventionally, supported Pt-catalysts are produced by wet impregnation of a support material. ${ }^{2-6}$ However, in some cases when using this method, agglomeration and low dispersions (number of surface $\mathrm{Pt}$ atoms/total number of $\mathrm{Pt}$ atoms) were

${ }^{a}$ Technische Universität Berlin, Strasse des 17. Juni 124, 10623 Berlin, Germany. E-mail: rinyyolandha@mailbox.tu-berlin.de; schomaecker@ tu-berlin.de

${ }^{b}$ Fritz Haber Institute of the Max Plank Society, Faradayweg 4-6, 14195 Berlin, Germany

$\dagger$ Electronic supplementary information (ESI) available. See DOI: $10.1039 / \mathrm{c} 2 \mathrm{jm} 15468 \mathrm{~d}$ observed. $^{7}$ Another attempt that has been frequently used is synthesizing both Pt-nanoparticles and the support material simultaneously. ${ }^{8,9}$ Unfortunately, this results not only in poor control of metal particle size and dispersion but it is also difficult to explain the influence of the preparation parameters on the performance of the catalysts.

Microemulsions ( $\mu$ Es) are used as excellent mediums to synthesize Pt-metal catalysts due to the simple control of the size and shape of the nanoparticles ${ }^{10-13}$ by adjusting parameters such as the water to surfactant ratio $(\omega)$, kind of surfactant, kind of precursor, initial concentration of metal salt, etc. The fundamental aspect of the synthesis of nanostructures using reverse micelle $\mu \mathrm{E}$ is in the collision and exchange of water droplets as depicted in Fig. S1 (ESI $\dagger$ ). When a $\mu$ E containing Pt-precursor is mixed with a $\mu \mathrm{E}$ containing reducing agent, a very fast collision and exchange between the droplets occurs continuously due to the dynamic nature of the water droplets in the $\mu \mathrm{E}$ system. The reduction of the Pt-precursor takes place during the exchange of the water droplets. Once the solution becomes supersaturated, the nuclei of platinum nanoparticles are generated and then the growth of the particles takes place inside the water pool until the unstable particles are produced. These unstable particles then agglomerate to form bigger particles and after subsequently ripening they become a stable crystal nanoparticle. However as previously mentioned, it is far better to deposit the metal nanoparticles onto a support material to increase the thermal and mechanical stability.

Several methods to deposit Pt-nanoparticles from water pools of water/oil microemulsions have been reported. One uses an organic solvent to destabilize the micelles. ${ }^{14}$ The support is added to the nanoparticle suspension and the microemulsion is destabilized by addition of an organic solvent. The catalyst suspension is then stirred, filtered, washed and calcined. By this method, the 
size of the produced nanoparticles is in the range of $20-40 \mathrm{~nm}$ with agglomeration. Another method is synthesizing the support simultaneously with the nanoparticles. ${ }^{15}$ The drawback of this method is that some of the metal particles become completely embedded in the supporting metal oxide, which reduces the available surface area of the active phase. The size of produced nanoparticles is in the range of $4.7-34.5 \mathrm{~nm}$, also with agglomeration. A third method is redispersion of nanoparticles in aqueous surfactant solution. ${ }^{13}$ The TEM images from the latter method showed some large Pt nanoparticles $(10-80 \mathrm{~nm})$ on the support with a high degree of agglomeration.

In this paper, we introduce a novel and simple method to prepare highly active and stable supported $\mathrm{Pt}$ nanoparticles at room temperature, namely thermal destabilization of microemulsion. The characteristic features of this method are: firstly, the ability to design the size and the shape of nanoparticles and secondly, the ability to control the dispersion of designed nanoparticles on the support during the deposition process. The first feature is carried out by choosing the appropriate surfactant, co-surfactant, reducing agent, and metal precursor with their proper concentrations. The second feature is done by adjusting the rate of heating, the choice of support material, and the mixing conditions to create a well mixed system. The substances in the first and second features can be appropriately chosen by conducting various test experiments as described in the Results and discussion section. Before applying the second one, the phase diagram of microemulsions needs to be studied to determine the temperature range of deposition (see upper right in Fig. 1).

The strategy in the deposition process is to utilize the path of temperature induced change of microemulsion phase behavior, which changes the 1-phase system to 2-phase (bottom right in Fig. 1). At this point of change (point $b$ ), the micelles start to destabilize (the monolayer of surfactant molecules is broken). The opening of the micelles occurs simultaneously and the nanoparticles are released. Without letting the agglomeration of the released nanoparticles take place, at this juncture we take the opportunity to deposit the nanoparticles directly to the support material. This way, Pt particles can be evenly deposited on both the surface and the pores of the support material whilst retaining the size and the shape of nanoparticles. Therefore, by implementing this method it is possible to produce small, multifaceted nanoparticles well dispersed onto support material (almost) without agglomeration.

The advantages of using this method are the following: (1) there is no need of a protecting or capping agent either in producing multifaceted nanoparticles or in depositing them onto the support to prevent agglomeration, which other researchers do use, ${ }^{16-19}(2)$ one can overcome the difficulty in controlling and terminating the growth during the initial stages, in order to obtain monodisperse size distribution, ${ }^{20}$ by stopping the reaction and putting the particles directly onto the support; (3) it is possible to reuse the surfactant and organic solvent, thus overcoming the hypothetical drawback that the $\mu \mathrm{E}$ method employs
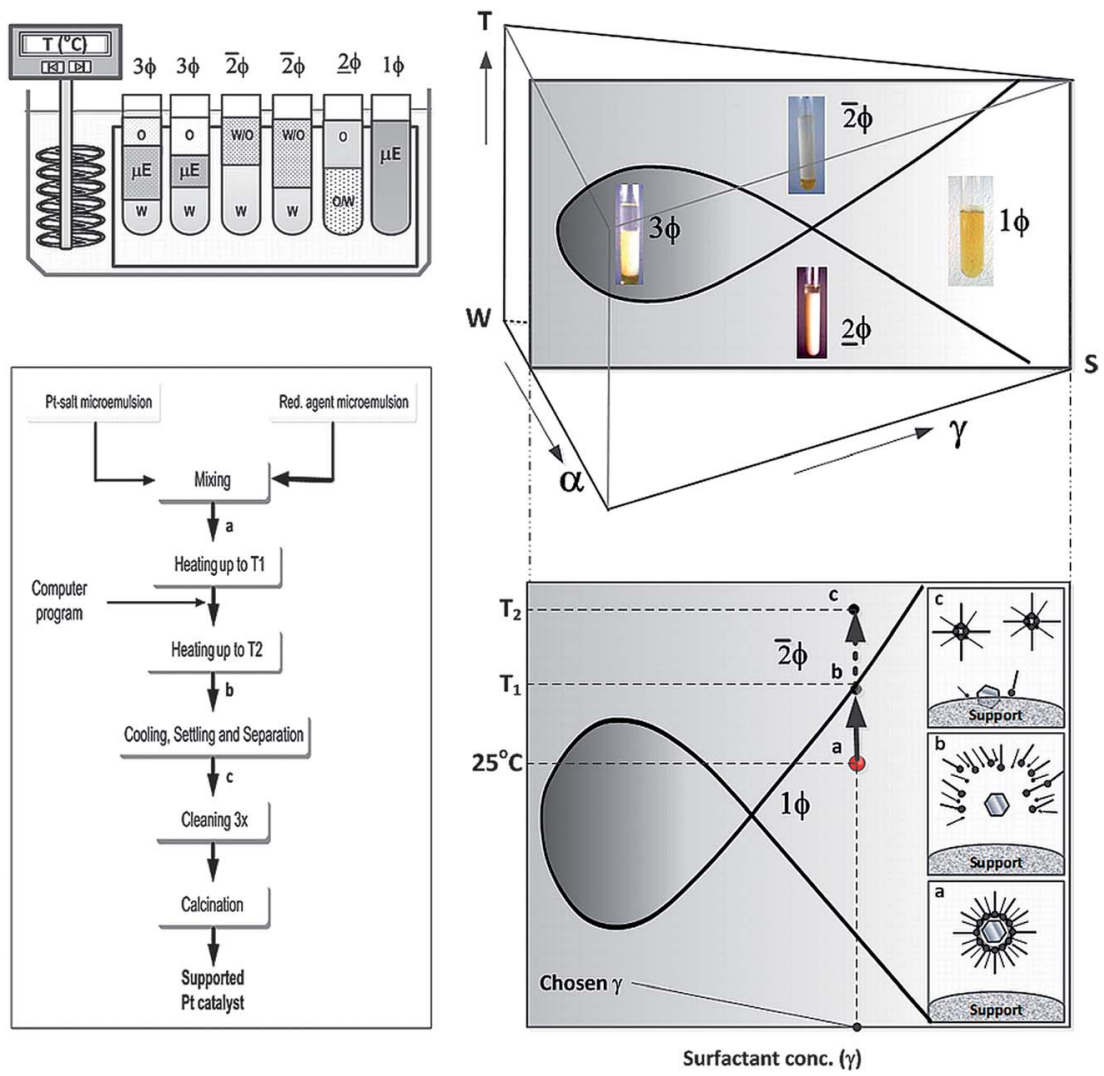

Fig. 1 Principle of the deposition process for Pt nanoparticles via thermo-destabilisation of $\mu \mathrm{E}$ : schematic phase prism (upper right), schematic experimental setup for phase behaviour observation (upper left), flowchart of synthesis (bottom left), and illustration of the deposition process. 
a large amount of surfactant and organic solvent; ${ }^{21}$ and (4) by choosing the proper surfactant, the synthesis and deposition process can be carried out in the range from room temperature to an only little higher temperature, thus saving energy costs. To reemphasize, not only is this synthesis method simple and inexpensive but also allows unrestricted control over the size and shape of nanoparticles as well as the dispersion on the support material.

\section{Experimental section}

\subsection{Materials}

The chemicals used in the preparation of Pt nanoparticles were the following: hexachloroplatinic acid hydrate (99.9\%, SigmaAldrich) as the platinum precursor, hydrazine monohydrate (98\%, Sigma-Aldrich) as the reducing agent, cyclohexane ( $\geq 99.5 \%$, Carl-Roth) as the oil phase and 1-pentanol ( $\geq 98 \%$, Carl-Roth) as the co-surfactant. The surfactants were the following: (1) non-ionic surfactants: Triton X-100 (100\%, SigmaAldrich) and Span 80 ( 70\%, Sigma-Aldrich); (2) anionic surfactant: AOT (98\%, Aldrich); and (3) cationic surfactant: CTAB ( 99\%, Sigma). All the chemicals above were used without further purification. Different kinds of support materials were used in deposition of the platinum nanocatalysts: $\gamma-\mathrm{Al}_{2} \mathrm{O}_{3}$ (Alfa Aesar and Sigma-Aldrich), $\alpha-\mathrm{Al}_{2} \mathrm{O}_{3}$ (Alfa Aesar), $\mathrm{SiO}_{2}$ (Sigma-Aldrich) and self-prepared SBA-15 according to the method reported by Zhao et al. ${ }^{22}$ All supports were pre-calcined before use. Acetone ( $\geq 99.8 \%$, Carl Roth) as the washing agent was used as received. The chemicals used for the hydrogenation reactions were methanol ( $\geq 99.9 \%$, Carl Roth) as a solvent and $\alpha$-methyl styrene (99\%, Aldrich) as a reactant; both were used as received.

\subsection{Catalyst preparation}

Phase behaviour of microemulsion systems. Prior to synthesis of supported Pt nanoparticles, the phase diagram of the microemulsion needs to be established. In principle, we want to find a composition which can produce a microemulsion with small droplet size at room temperature, and also to select the proper temperature for the destabilization process.

The mass fraction of oil in the microemulsion system is defined by $\alpha$. The mass fraction of surfactant is determined by $\gamma$. Because we use a co-surfactant to stimulate rapid coalescence, ${ }^{1}$ the surfactant is considered now as a pseudo-single-phase. Hence, $\gamma=\left(m_{\mathrm{s}}+m_{\mathrm{co}-\mathrm{s}}\right) /\left(m_{\mathrm{w}}+m_{\mathrm{o}}+m_{\mathrm{s}}+m_{\mathrm{co}-\mathrm{s}}\right)$. The mass ratio of co-surfactant to surfactant is defined by $\delta$. The molar ratio of water to surfactant indicating the size of a water droplet is defined by $\omega$. The complete phase behavior of microemulsions is usually depicted by a ternary-phase diagram. It is constructed using the relative amounts of the three components of microemulsions, i.e. water phase, oil phase and surfactant. At constant pressure, the ternary phase diagram can be represented as a prism with the Gibbs triangle as the bottom part, and temperature $(T)$ as the ordinate as shown in Fig. 1 (upper right). The composition variables at each side of the Gibbs triangle are expressed by $\alpha$ and $\gamma$. It is rather complex and time consuming to construct such a phase prism diagram. Because we only want to focus on the phase evolution at different temperatures, it is not necessary to determine the entire coexistence region and phase boundaries within the Gibbs triangle. By observing the phase behavior of microemulsions (at fixed value of $\alpha$ and various $\gamma$ ) at different temperatures, a 'fish diagram' can be established, as shown in Fig. 1 (right side). Experimentally, this diagram is constructed by conducting an experiment as illustrated in Fig. 1 (upper left). Test tubes were filled with microemulsions with different composition of surfactants $(\gamma=0.025-0.85)$ at the fixed value of $\alpha$. The first trial is $\alpha=0.5$ and the second is $\alpha=0.92$. The latter $\alpha$ is chosen by rigorously conducted trial and error experiments, because we want to reduce more the water droplet size. The total volume was $7.5 \mathrm{ml}$. The test tubes were immersed in a thermostatted-water glass bath. The phase behavior was observed by increasing the temperature every $5{ }^{\circ} \mathrm{C}$ (holding for 15 minutes) from $10^{\circ} \mathrm{C}$ to $70^{\circ} \mathrm{C}$. This procedure was applied for each different type of surfactant.

Synthesis of nanoparticles and deposition process. The microemulsion system for preparing $\mathrm{Pt}$ nanoparticles comprises the water phase with either hexachloroplatinic(Iv) acid $\left(\mathrm{H}_{2} \mathrm{PtCl}_{6}\right)$ or hydrazine, Triton X-100 as the surfactant, pentanol as the cosurfactant and cyclohexane as the oil phase. The compositions used in the experiments are listed in Table 1, except in the experiment where the concentration is varied. The synthesis of the platinum nanoparticles was carried out in a $200 \mathrm{ml}$ doublewall glass reactor equipped with a three parallel two-blade impeller. The hydrazine microemulsion was added slowly to the reactor, which had already been filled with the Pt salt microemulsion, by a micropump $\left(0.2 \mathrm{ml} \mathrm{s}^{-1}\right)$. The mixture was stirred at $700 \mathrm{rpm}$ for 30 minutes at room temperature to form colloidal stabilized $\mathrm{Pt}$ nanoparticles. Then the pre-calcined support $\left(500{ }^{\circ} \mathrm{C}\right.$ for 2 hours) was added to the mixture, and the $\mathrm{Pt}$ nanoparticles were deposited over the support material by heating up the microemulsion to the destabilization temperature. To reach the destabilization temperature, different heating rates were used. (The temperature of the reactor system was adjusted by a thermostat, which was connected to a computer program to regulate the heating rate.) After the deposition process, the mixture was cooled down. After all the supported catalysts precipitated, they were carefully separated from the solution and washed three times with pure acetone and subsequently calcined. The flowchart of this synthesis method is presented in Fig. 1 (bottom left).

Activity testing in hydrogenation reaction. To ensure the accuracy of activity testing, all catalysts were kept away from contact with air. We tested the catalysts in the hydrogenation of

Table 1 The composition of microemulsions used in the experiments

\begin{tabular}{|c|c|c|c|c|}
\hline & \multirow[b]{2}{*}{ Microemulsion I } & \multirow[b]{2}{*}{ Microemulsion II } & \multicolumn{2}{|l|}{$\% w t$} \\
\hline & & & $\begin{array}{l}\omega_{1}= \\
12.96\end{array}$ & $\begin{array}{l}\omega_{2}= \\
14.88\end{array}$ \\
\hline Water phase & $2.55 \mathrm{mM} \mathrm{H}_{2} \mathrm{PtCl}_{6}$ & $18.35 \mathrm{mM}$ hydrazine & 5.6 & 15 \\
\hline Surfactant & Triton X-100 & Triton X-100 & 64.4 & 15 \\
\hline Co-surfactant & Pentanol & Pentanol & 15 & 30 \\
\hline Oil phase & Cyclohexane & Cyclohexane & 15 & 30 \\
\hline
\end{tabular}


a-methyl styrene (AMS) at $20^{\circ} \mathrm{C}$ and 1.1 bar. The hydrogenations were performed in a $200 \mathrm{ml}$ double-walled glass reactor equipped with glass baffles and a gas-dispersion stirrer. The scheme of the hydrogenation reactor set-up is presented by Milano et al. ${ }^{23}$ Hydrogen and nitrogen gas lines were attached to the reactor. A vacuum pump was attached to evacuate the reactor. The reactor system was connected to a pressure controller (to keep the pressure constant) and a flow meter (to measure the hydrogen required to replace the amount of hydrogen consumed by the reaction). Both were connected to a computer with a control program.

The supported platinum catalyst was added to the reactor, subsequently with adding $100 \mathrm{ml}$ methanol as a solvent and $1 \mathrm{~g}$ AMS, respectively. The reactor was closed and sealed followed by the reduction of pressure down to 0.2 bar (and holding it for 5 minutes in order to check for gas leakage). Having ensured that there was no leakage, the mixture was stirred at $600 \mathrm{rpm}$ and 20 ${ }^{\circ} \mathrm{C}$ for 20 minutes. The reactor was evacuated three times, by reducing the pressure to $180 \mathrm{mbar}$, and then refilled with nitrogen. Afterward the reactor was evacuated to $180 \mathrm{mbar}$ and filled with hydrogen until it reached a total pressure of 1.1 bar. The computer program was started along with stirring the mixture at $1200 \mathrm{rpm}$. The reaction was stopped when the data acquisition indicated that there was no further hydrogen consumed in the reaction. A representative reaction profile is presented in Fig. S3†.

Based on the fact that one molecule of hydrogen is needed per one double bond of AMS $\left(n_{\text {product }}=n_{\mathrm{H} 2}\right)$, the moles of product can be calculated by the moles of consumed hydrogen. The rate of product formation is calculated from eqn (1), based on the ideal gas law, using the rate of hydrogen consumption which was measured by the flow meter:

$$
\frac{\mathrm{d} n_{\text {product }}}{\mathrm{d} t}=\frac{P}{R T} \frac{\mathrm{d} V\left(\mathrm{H}_{2}\right)}{\mathrm{d} t}
$$

By dividing the value of $\mathrm{d} n_{\text {product }} / \mathrm{d} t$ by the amount of Pt metal on the support (analyzed by ICP), we obtain the value of activity (eqn (2)):

$$
\operatorname{Activity}\left(\mu \mathrm{mol} \mathrm{g} \mathrm{g}_{\mathrm{Pt}}^{-1} \mathrm{~s}^{-1}\right)=\frac{\mathrm{d} n_{\text {product }}}{\mathrm{d} t \cdot \mathrm{m}_{\mathrm{Pt}}}
$$

Therefore, to measure the performance of the catalyst we use activity instead of TOF because we assume that all the metal atoms deposited on the support are surface active. In all of our catalytic testing experiments, the reaction rates were compared at the same reaction conditions. A few repeated experiments show that the reproducibility of the rate was found to be less than $5 \%$ error.

Characterization and analysis methods. The shape, size, and lattice structure of the $\mathrm{Pt}$ nanoparticles were investigated by a transmission electron microscope (TEM) at an FEI Titan 80300 (sub-Angstrom resolution, able to investigate at atomic scale), and also with a FEI Tecnai G2 S-Twin TEM and Philips CM200/FEG high-resolution TEM (HRTEM) operated at $200 \mathrm{kV}$. Both microscopes are equipped with an energy dispersive $\mathrm{X}$-ray detector (EDX). The TEM grids were prepared for imaging by placing a small drop of the specimen solution on a copper grid having an amorphous carbon film less than $20 \mathrm{~nm}$ thick and allowing it to dry completely in air at ambient temperature. Pt contents of the support catalysts were analyzed by an ICP-OES Element 2 (Varian) at low resolution (sample gas $0.8631 \mathrm{~min}^{-1}$; plasma power $1350 \mathrm{~W}$ ).

\section{Results and discussion}

To obtain stable and active supported Pt catalysts, optimal conditions for synthesis and deposition have to be found. In this section, the impact of different parameters will be discussed by comparing the catalytic activity in the hydrogenation of AMS. This discussion is supported by a detailed analysis of the catalyst structure by conventional methods.

\section{Choosing the surfactant and co-surfactant}

It has been shown by various studies that the choice of surfactant is critical to the size, shape and stability of the prepared particles. ${ }^{24}$ The rigidity of the surfactant film plays a crucial role in guiding the morphology of the product formed ${ }^{25}$ In our work, we consider not only these factors, but also the surfactant's ability to produce one phase microemulsions at room temperature and the temperature range of destabilization. The phase diagrams of microemulsions containing different surfactants are shown in Fig. S2 (ESI $\dagger$ ). Considering that the microemulsions obtained by ionic surfactants (Fig. S2c and d $\dagger$ ) cannot produce one phase regions at room temperature and Span 80-containing microemulsions change their phase at nearly room temperature (Fig. S2b $†$ ), we decided to choose Triton X-100 as the surfactant (Fig. S2a $\uparrow$ ) for further experiments. To ensure that the shape of nanoparticles is only controlled by the surfactant, the influence of other parameters must be annulled. This is achieved by adding the co-surfactant and choosing the solvent that can promote a fast growth rate of nanoparticles in the reverse micelle. We decided to use pentanol as a co-surfactant because it not only caused rapid microemulsion formation, but also rapid coalescence. ${ }^{26}$

\section{Choosing the solvent}

The solvent can affect the hydrodynamic radius and thickness of the surfactant layer of the micelles. The more bulky the structure of the solvent (larger molecular volume), the more rigid is the surfactant curvature and the slower the micellar exchange will be. In our research, we chose a less bulky solvent cyclohexane, because it is able to penetrate the surfactant tails efficiently during micellar exchange. ${ }^{25}$ As a result, the growth rate of nanoparticles is faster, thus ensuring that the size and the shape of produced nanoparticles is affected only by the surfactant. In case another hydrocarbon is selected as the solvent, a suitable nonionic surfactant has to be chosen according to the well known relationships in the phase behavior of the water oil surfactant system.

\section{Choosing the precursor}

In this study, we chose a strong reducing agent $\mathrm{N}_{2} \mathrm{H}_{4}$ to ensure a fast reduction process in the nucleation process so that the shape in the formation of the Pt crystal is controlled only by the surfactant. However, we had no particular reason in choosing 
$\mathrm{H}_{2} \mathrm{PtCl}_{6}$ as the $\mathrm{Pt}$ precursor, although in our recent study we found that using $\mathrm{K}_{2} \mathrm{PtCl}_{4}$ as the $\mathrm{Pt}$ precursor results in a different shape of the $\mathrm{Pt}$ particle.

\section{The effect of the heating rate}

The critical step of preparing the supported catalyst by thermodestabilization of the $\mu \mathrm{E}$ method is the heating process. The mixing of both microemulsions containing hexachloroplatinic acid and hydrazine was performed at room temperature. The produced nanoparticles were released from the water pools by increasing the temperature of the mixture. In this work, we tested two different ways of heating up the mixture to release the nanoparticles. The first way is to increase the temperature with a constant rate $\left(1,0.25\right.$ or $\left.0.067^{\circ} \mathrm{C} \mathrm{min}^{-1}\right)$ and the second way is to increase the temperature stepwise $\left(1^{\circ} \mathrm{C}\right.$ per $\left.15 \mathrm{~min}\right)$. The catalyst prepared at the fastest heating rate has the highest activity (Fig. 2). The explanation for this event is related to the residence time of unprotected nanoparticles in the microemulsions. The faster the heating rate, the faster is the opening of the micelles and the shorter they stay freely in the destabilized microemulsions. As a result, the tendency of the particles to agglomerate is reduced, thus they are more active. By observing this, we chose the fastest heating rate (according to our thermostat capacity) to destabilize the microemulsions.

\section{Effect of the support feeding prior to deposition process}

To optimize the deposition process, we tested the method of feeding the support into the reactor prior to the deposition process, i.e. before or after the opening of micelles. We observed that the catalyst prepared by feeding the support into the reactor after opening the micelles was less active (Fig. S4†). Undoubtedly, feeding the support into the reactor after opening the micelles allows the particles to agglomerate before their contact with the support. This strongly confirms the result from Fig. 2 that the nanoparticles tend to agglomerate if they are not immediately deposited and stabilized on the support. In all further experiments we fed the support into the reactor before opening the micelles.

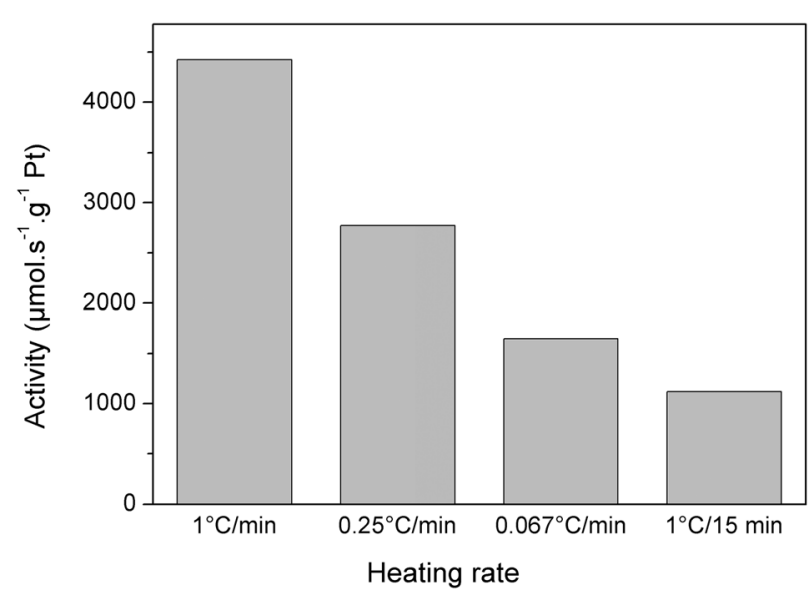

Fig. 2 The activities of the produced catalysts prepared at different heating rates.

\section{Effect of the growing time}

The most interesting part of our method is that we can produce a catalyst according to the desired particle growth by stopping the reaction and immediately putting the particles on the support. This growth interruption may result in nanoparticles with smaller diameter. In this method, this aspect can be further developed because many authors have found that the shape and size of $\mathrm{Pt}$ nanoparticles change during the growing time. ${ }^{1,25-27}$ The growth mechanism during the course of reaction in microemulsions has been proposed by some groups. ${ }^{20,27}$ The stages of nucleation and growth which are related to controlling the size and shape of $\mathrm{Pt}$ nanocrystals have been well illustrated by Tsung et al. ${ }^{28}$ It also has been reported that nearly monodisperse size distribution can be obtained at the stage of nucleation and growth either by stopping the reaction or by supplying a reactant source to maintain a saturated condition during the course of the reaction. ${ }^{20}$ The formation of $\mathrm{Pt}$ particles starts when $\mathrm{Pt}^{4+}$ ions come in contact with the reducing agent $\mathrm{N}_{2} \mathrm{H}_{4}$, through intermicellar exchange or coalescence, according to the following reaction:

$$
\mathrm{H}_{2} \stackrel{+\mathrm{PV}}{\mathrm{Pt}} \mathrm{Cl}_{6}+\mathrm{N}_{2} \mathrm{H}_{4} \rightarrow \mathrm{Pt}^{0}+6 \mathrm{HCl}+\mathrm{N}_{2}
$$

We observed that the activity of the catalyst depends on the size of the particles (Fig. 3). From the TEM image in Fig. 3a, one can see that there are only a few atoms grouped in nanoparticles after 1 minute. The activity of this catalyst is low because few active sites are available to promote the surface reaction. It seems that the status of these particles has passed the nucleation stage and is already in crystal growth (see Fig. S1 $\dagger$ ). The activity of the catalyst produced in 15 minutes is lower than that produced within 1 minute. Fig. $3 \mathrm{~b}$ implies that although many particles are formed, they are probably in the transition process of agglomeration and ripening to form a defined crystal structure. Therefore, in the deposition process, they presumably spread over the support material but only form a two-dimensional structure which has less active sites. Compared to the particles obtained after 15 minutes, after 30 minutes, a three-dimensional (3D) crystal structure has been formed, characterized by a clear $2 \mathrm{D}$ hexagonal shape (Fig. 3c). The hexagonal structure can be

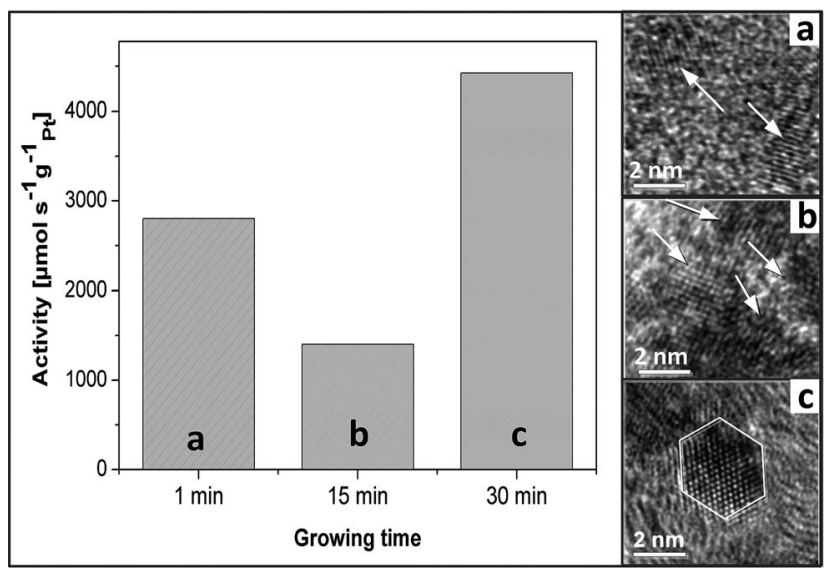

Fig. 3 The activities of the produced catalysts prepared at different growing times and the corresponding TEM images: a, b, and c are the $\mathrm{Pt}$ particles after growing for $1 \mathrm{~min}, 15 \mathrm{~min}$ and $30 \mathrm{~min}$ respectively. 
predicted to be a truncated octahedral based on the Wulff construction. ${ }^{29}$ In the TEM investigations, the Pt nanoparticles in the water phase were moving when they were irradiated by the electron beam in TEM, therefore the high-resolution TEM images are not very clear. But based on the similarity of our TEM images and the Fast Fourier Transform pattern with the results from other publications ${ }^{29-32}$ (Table $\mathrm{S} 2 \dagger$ ) which indicated it is a truncated octahedral, we would like to conclude that our particle is also a truncated octahedral. This multifaceted crystal has atomic steps and terraces which can enhance the activity of a catalyst; ${ }^{31}$ hence, the particles which grow for 30 minutes show higher activity.

The nuclei may grow by reducing the $\mathrm{Pt}^{4+}$ ions, mainly on the most catalytically active $\{111\}$ surfaces, to form truncated octahedral nanoparticles. ${ }^{33}$ This well defined crystal shape has more faces and causes the higher concentration of atomic step edges that are readily available to participate in chemical reactions. It is most likely that after 30 minutes particles have already reached a stable size, wherein they will grow by combining with small unstable nuclei and not by collisions with other stable particles. ${ }^{20}$

\section{The effect of the initial concentration ratio}

In designing the nanoparticles inside the micelles, as it has been studied, ${ }^{34}$ the initial concentrations of the precursor and reducing agent also need to be considered. It has been reported that with increasing the concentration of hydrazine while the concentration of metal salt is kept constant, a decrease in particle size is observed. ${ }^{9}$ Conversely, increasing the concentration of the metal precursor while the concentration of hydrazine is kept constant can also increase the particle size. ${ }^{35}$ We observed that the highest activity was achieved by the catalyst produced with a 100 -fold excess of reducing agent (Fig. S5†). This indicates that the more complete (without $\mathrm{Pt}^{4+}$ left in the solution) and faster the precipitation of nanoparticles facilitated by giving excess reducing agent, the more active is the catalyst. This is in agreement with the results reported by Niesz et al. ${ }^{36}$ which show that faster reduction of $\mathrm{Pt}$ ions leads to small particles.

\section{The deposition process by thermal-destabilization method}

The phase diagrams which show the temperature range of particle deposition from microemulsions with $\alpha_{1}=0.5$ and $\alpha_{2}=0.92$ are depicted in Fig. 4 . Increasing the water content in microemulsions causes a shift of the phase boundary to the higher temperature thus a larger range of deposition temperature. It signifies that the bigger size of the reverse micelles (which is caused by the higher proportion of water) needs a bigger amount of energy to destabilize. By increasing the temperature of the microemulsion system (tracking the arrow in Fig. 4) the transfer of Pt nanoparticles from inside the micelles onto the support was successfully done with almost no agglomeration, which is verified by the results in Fig. 5.

The droplet size is an important parameter because it controls the size of the produced nanoparticle and thus influences the activity of the catalyst. Experimentally, it is measured by Dynamic Light Scattering (DLS). However, we did not measure it directly because according to several studies it is dominantly characterized by the $\left[\mathrm{H}_{2} \mathrm{O}\right] /[$ Surfactant $]$ molar ratio, defined as $\omega .^{24,37}$ There is no general formulation that correlates $\omega$, size of droplets and size of the nanoparticles, because every microemulsion has its own characteristics. However, it can be generalized that the droplet size is proportional to $\omega$. The major change in the particle size is obtained at low $\omega .{ }^{20} \mathrm{We}$ study the influence of $\omega$ on the size of the produced nanoparticles by TEM. The TEM pictures in Fig. 5 indicate that the size of particles produced for $\omega_{1}=13$ is significantly smaller than for $\omega_{2}=15$. This is in agreement with the results that have been published which show a larger size of the particle for higher values of $\omega .{ }^{25,38,39}$ The corresponding histograms in Fig. 5 show that the size distributions of nanoparticles produced at both $\omega$ values are rather narrow and exhibit the features of a log-normal distribution. It has been reported that the uniformity of the size distribution is achieved through a short nucleation period and this can be achieved by feeding a reactant continuously to maintain saturated conditions during the course of the reaction constant. ${ }^{20}$ This indicates that in both cases, the amount of reducing agent (8-fold excess) is enough to promote a short nucleation step.

The primary factors of the higher activity of supported $\mathrm{Pt}$ catalysts produced from our experiments are the size, the shape and the dispersion. It is most likely that the small size of the Pt particles is caused by the effect of the reducing agent. The reduction process by hydrazine can be completed instantly, in comparison to the use of pure hydrogen which is a much slower process. ${ }^{9}$ As a general rule, a fast nucleation process will result in
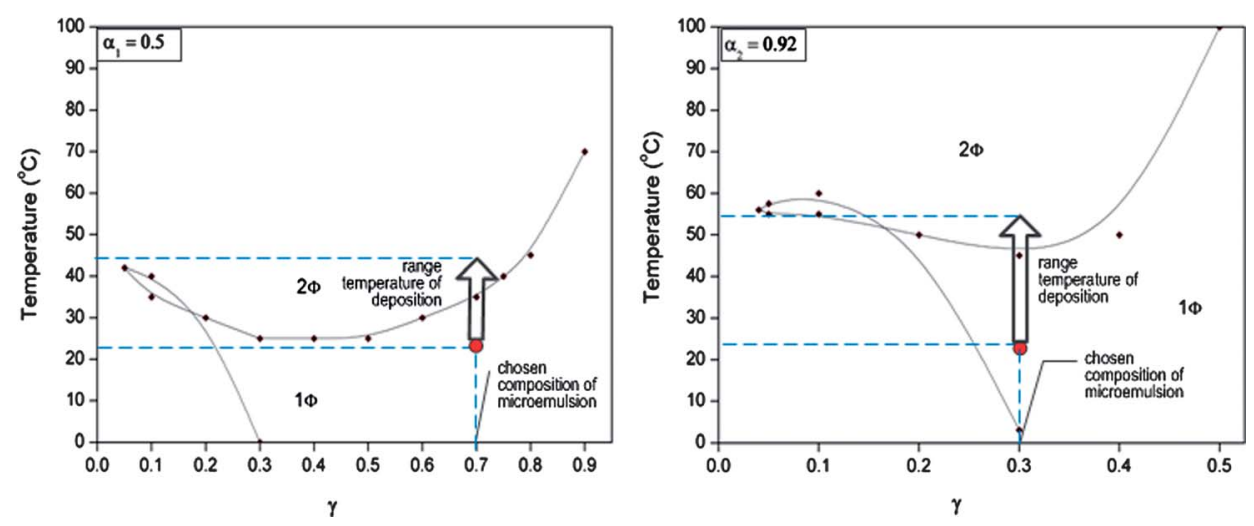

Fig. 4 Phase diagrams of microemulsions and the ranges of temperature of deposition, $\alpha_{1}=0.5$ (left) and $\alpha_{2}=0.92$ (right). 

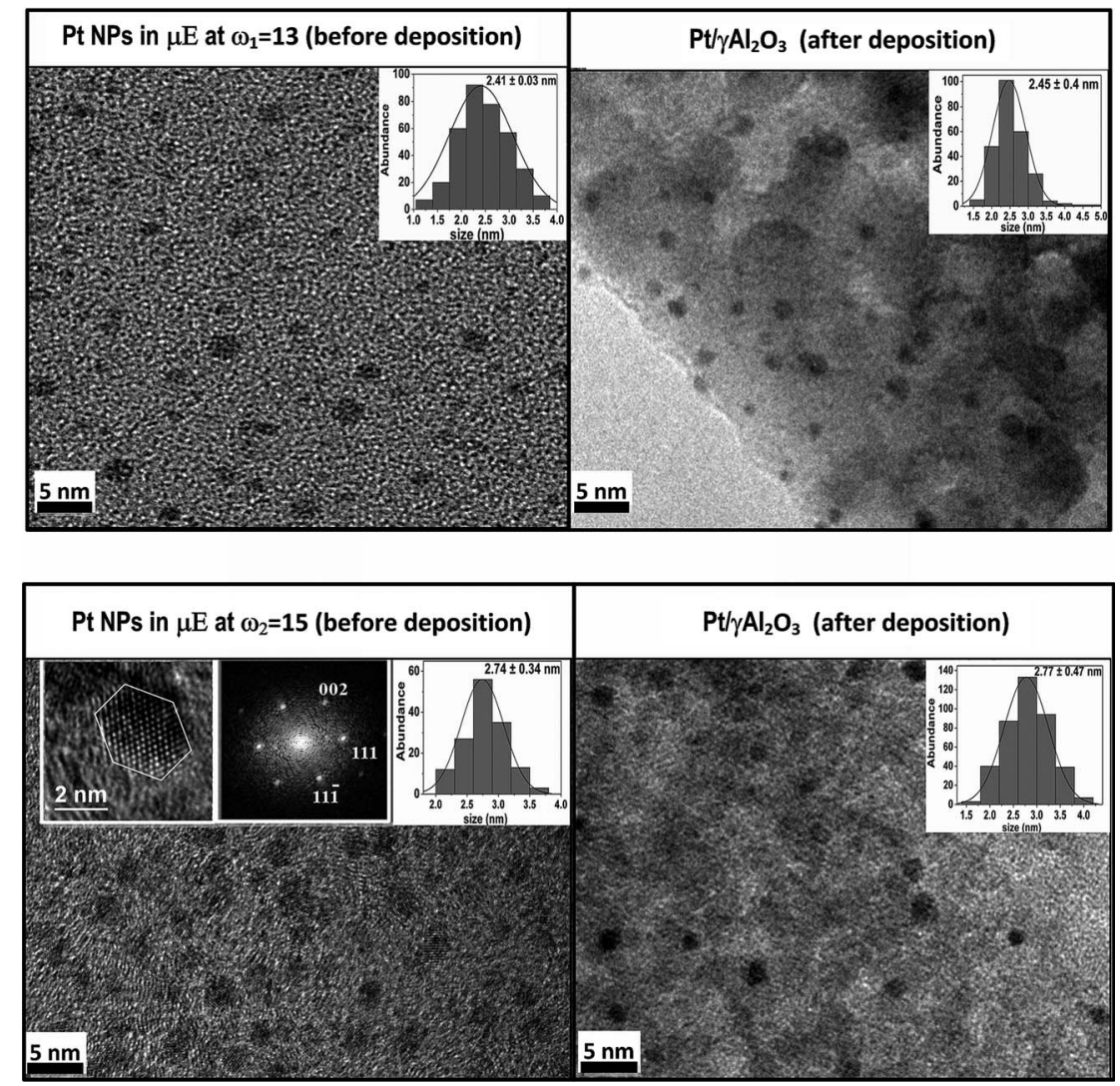

Fig. 5 TEM images of Pt nanoparticles inside the microemulsions before and after the deposition process at different $\omega$ values and their corresponding size distributions.

the production of small particles. The small size is also contributed by the presence of the co-surfactant, pentanol. It was concluded by Eastoe et al. ${ }^{24}$ that the addition of a co-surfactant not only leads to a higher fluidity of the interfacial film, thus increasing the rate of intermicellar exchange, but also leads to a higher curvature of the droplets, so smaller particles are obtained.

The hexagonal shape of the particles (Fig. 5, bottom left, left inset) is produced primarily because of the head group of the surfactant rather than the reducing agent. As mentioned previously, in synthesis by the microemulsion method, the shape of the nanoparticles is strongly influenced by the surfactant. ${ }^{25} \mathrm{On}$ the other hand, the reducing agent can also affect the shape of the produced nanoparticles. A weak reducing agent effectively isolates the nucleation and growth events allowing control over the size and shape. ${ }^{40}$ In the case of using a strong reducing agent like hydrazine, the dominant factor will be the surfactant. We use a strong reducing agent, hydrazine, with 8-fold excess in our synthesis to ensure fast growth; hence there is no influence in governing the shape of nanoparticles. It has been reported that the use of Triton X-100 as a surfactant to different kinds of metal precursors can produce nanoparticles with different shapes such as spherical, nanofibers, nanobelts, rodlike $e^{41}$ and nanocubes. ${ }^{38}$ Therefore, when using $\mathrm{H}_{2} \mathrm{PtCl}_{6}$ as a precursor, Triton X-100 dominantly directs the seed to the equal growth of $\{111\}$ and $\{100\}$ facets which finally form truncated octahedrals which look hexagonal in the TEM image ${ }^{42,43}$ (Fig. 5, bottom left, left inset). As mentioned above, not only from the Wulff construction do we predict that our nanoparticles are truncated octahedrals, but also from the similarities to other results as shown in Table S2 (ESI + ).

This is also supported by the Fourier transform pattern of the particle (Fig. 5, bottom left, middle inset), which shows the same pattern as has been reported to be a truncated octahedron. ${ }^{29}$ The equal or isotropic growth produced by nonionic surfactants like Triton X-100 was also proposed in earlier studies. ${ }^{38,41}$

It has been stated that nanoparticles are small and not thermodynamically stable against crystal growth. To finally produce stable nanoparticles, the growth of these nanoparticles must be arrested during the reaction either by adding surface protective reagents, such as organic ligands, or inorganic capping materials. ${ }^{20}$ Interestingly, by the thermo-destabilization of microemulsion we can produce supported Pt particles with a narrow size distribution without a protective or capping agent. Table 2 presents different methods to prepare supported $\mathrm{Pt}$ particles. Some researchers applied different deposition methods of particles from microemulsions such as by solvent destabilization or redispersion (Boutonnet, Yashima, and Hanna et al.) but still big particles and agglomerates are produced with broad particle size distributions. Many have used capping agents in the microemulsion system yet still produced rather big particles and broad particle size distributions such as the results of Liu et al. and Ikeda et al. Bigger Pt particles are also produced from other methods such as impregnation, precipitation, sol-gel, rotating 
Table 2 The comparison between different methods of Pt-nanoparticle preparation

\begin{tabular}{|c|c|c|c|c|}
\hline Method & Author & $\begin{array}{l}\text { Capping } \\
\text { agent }\end{array}$ & $\begin{array}{l}\text { In situ support + NP } \\
\text { preparation }\end{array}$ & Result/particle size \\
\hline Impregnation & El. Sayed and $\mathrm{Yoo}^{44}$ & Yes & No & Ave. $10 \mathrm{~nm}$ \\
\hline Precipitation & Lee et $a l^{8}$ & Yes & Yes & Failed/agglomeration \\
\hline Sol-gel & Lee et $a l^{8}$ & Yes & Yes & $>50 \%$ of the pore structure shrunk \\
\hline Polyalcohol reduction & Liu et $a l^{45}$ & Yes & Yes & $3.5-11.5 \mathrm{~nm}$ \\
\hline Hydrolysis in $\mu \mathrm{E}$ & Ikeda et al. $^{15}$ & Yes & Yes & $4.7-34.5 \mathrm{~nm}$ \\
\hline Electrophoretic & Teranishi et al. ${ }^{47}$ & Yes & No & $30-32.5 \mathrm{~nm}$ \\
\hline Rampino and Nord & Petroski et al. ${ }^{48}$ & Yes & Yes & Ave. $12 \mathrm{~nm}$ \\
\hline Rampino and Nord & Eriksson et al. ${ }^{9}$ & Yes & Yes & $8-12 \mathrm{~nm}$ \\
\hline Solvent Destabilization & Boutonnet $^{49}$ & No & No & $10-35 \mathrm{~nm} /$ agglomeration \\
\hline Solvent destabilization & Yashima et al. ${ }^{14}$ & No & No & $20-40 \mathrm{~nm} /$ agglomeration \\
\hline Solvent destabilization & Hanna et $a l^{13}$ & No & No & 5-100 nm/agglomeration \\
\hline Redispersion & Hanna et al. $^{13}$ & No & No & 10-50/agglomeration \\
\hline
\end{tabular}

cathode, Langmuir-Blodgett, and Rampino and Nord, although they used capping agents.

\section{Effect of the support material and comparison with other catalysts}

In our synthesis we observe that the dispersion of particles on the support also depends on the properties of the support. The extreme difference in the obtained activity of catalysts supported on SBA-15 and $\mathrm{Al}_{2} \mathrm{O}_{3}$ indicates that in the thermo-destabilization method, the properties of the support material are crucial. It determines the responsiveness of the support to the nanoparticles released from the micelles during the deposition process. It is most likely that not only the high surface area of SBA-15 $\left(800 \mathrm{~m}^{2}\right.$ $\mathrm{g}^{-1}$ ), which accommodates the releasing of particles, but also the structure of the support are responsible for the activity. The well ordered channel structure of SBA-15 provides a good dispersion of the active phase on the surface; it can hinder Pt nanoparticles from sintering and thus promote the good contact between active sites and reactants. The TEM image in Fig. 6A shows that $\mathrm{Pt}$ nanoparticles distributed not only on the surface of SBA-15 particles but also inside the channels (see the inset). To confirm the location of the nanoparticles on the support material, we investigated the cross-section of our Pt catalyst with EDX as shown in Fig. S6†. The red line refers to the amount of Pt on the outer surface of the support while the blue line to the inner surface of the support. A little difference in height between the blue line and the red line shows that to such an extent $\mathrm{Pt}$ is also located inside the support. This also indicates that Pt metals are able to penetrate into the pores of the support during the deposition.

We have tried to verify the level of dispersion of our catalysts with the chemisorption method. Unfortunately, it was not successful because of the low loading of metal $( \pm 0.07 \%)$ and the small size of the Pt particles $( \pm 2.5 \mathrm{~nm})$. We did prepare low loadings of the metal purposely (by using a low concentration of Pt salt) because we want to produce the small size of NPs and also to keep them from agglomeration during the deposition process. For that reason, we analyzed the dispersion of the catalyst only by observing the TEM pictures which show that our
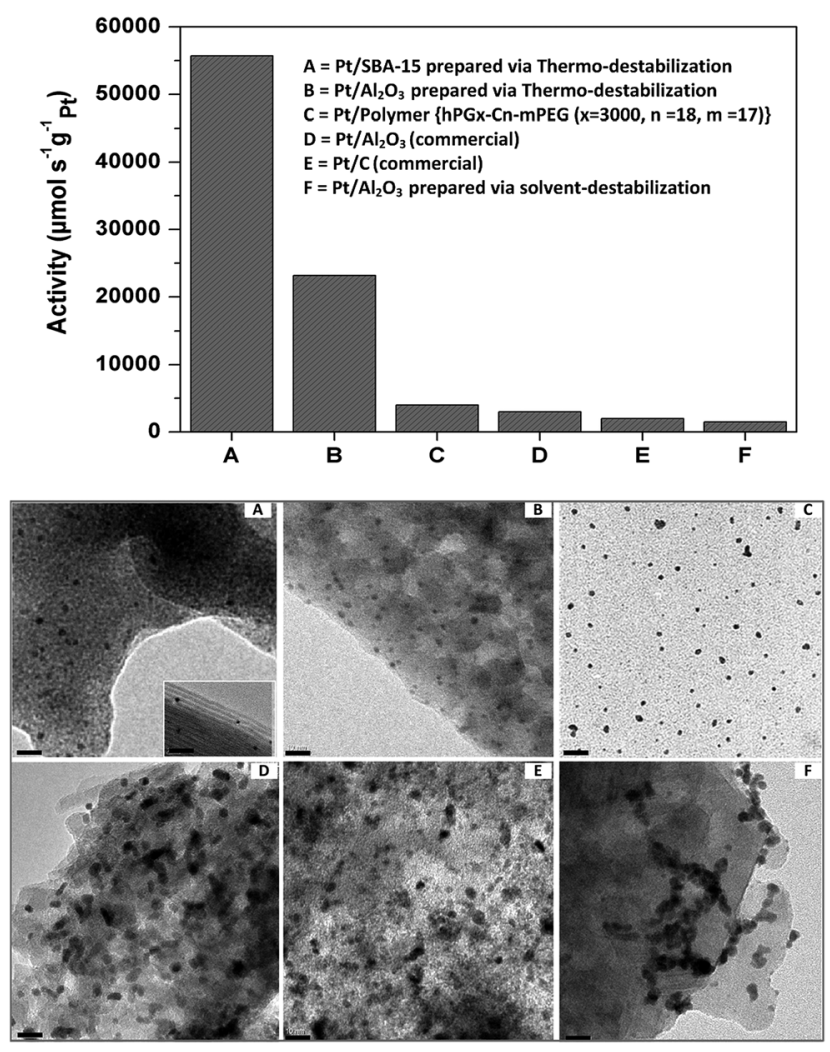

Fig. 6 The activities of the Pt catalysts (upper) and the corresponding TEM-images (bottom). The scale bars are $10 \mathrm{~nm}$.

catalysts are well distributed over the support materials. The particle size distributions are also narrow as shown in Fig. 5. We also compare our produced catalysts with other Pt catalysts, i.e. commercial ones and the one prepared by another method. To make sure that the catalysts are fully reduced, the commercial catalysts were pre-reduced with hydrogen at $300{ }^{\circ} \mathrm{C}$ for 3 hours before being tested. The activities of Pt/SBA-15 and $\mathrm{Pt} / \mathrm{Al}_{2} \mathrm{O}_{3}$ are 55000 and $7000 \mu \mathrm{mol}\left(\mathrm{g}_{\mathrm{Pt}^{-1}} \mathrm{~s}^{-1}\right)$ respectively while the commercial catalysts $\mathrm{Pt} / \mathrm{Al}_{2} \mathrm{O}_{3}$ and $\mathrm{Pt} / \mathrm{C}$ are 4000 and $3000 \mu \mathrm{mol}$ $\left(\mathrm{g}_{\mathrm{Pt}}{ }^{-1} \mathrm{~s}^{-1}\right)$ as shown in Fig. 6 . 


\section{Effect of calcinations}

Calcination of the supported catalyst needs to be optimized in order to avoid sintering. Fig. 7 shows the catalytic activity of catalysts prepared at different calcination temperatures (each temperature was held for two hours). It can be concluded that by increasing the temperature up to $500{ }^{\circ} \mathrm{C}$, Pt nanoparticles start to sinter on the support indicated by decreased activity. This can be seen from the corresponding TEM images which show the increasing size of the particles (Fig. 7b and c). Our observations are comparable to what has been published: Romero-Pascual et $a l .{ }^{50}$ reported that sintering platinum particles on alumina support happened after calcinations at $500^{\circ} \mathrm{C}$ for $2 \mathrm{~h}$ and at 600 ${ }^{\circ} \mathrm{C}$ for $24 \mathrm{~h}$, and Miller et al. ${ }^{51}$ showed that after $300{ }^{\circ} \mathrm{C}$ the dispersion of platinum on the support decreased drastically. Therefore, we conclude that the air calcination at $300{ }^{\circ} \mathrm{C}$ for 2 hours was sufficient to ensure the removal of the remaining surfactant from the synthesis process and to strengthen the bond of $\mathrm{Pt}$ to the support. This is confirmed by the stability test in Fig. 8 .

\section{Other parameters}

We also investigated other parameters such as filling rate of reducing agent into the reactor, stirring rate during synthesis and deposition processes, the use of baffles in the synthesis reactor, and kind of washing agent used to clean the catalyst after synthesis, but according to our observations, these variables have minor effects.

\section{Stability test}

To test the lifetime of our catalyst, we employed our $\mathrm{Pt} / \gamma-\mathrm{Al}_{2} \mathrm{O}_{3}$ in six consecutive hydrogenation reactions. We note that for the stability testing, we did not use Pt/SBA-15 (the best activity), because we synthesized it long after the stability test of the $\mathrm{Pt} / \gamma-\mathrm{Al}_{2} \mathrm{O}_{3}$, which has the highest reaction rate. We assume that $\mathrm{Pt} / \gamma-\mathrm{Al}_{2} \mathrm{O}_{3}$ is a representative catalyst for showing the ability of our method in producing a stable supported catalyst. Fig. 8 displays the stability performance of the catalyst in hydrogenation of AMS. By comparing the initial reaction rate (indicating the activity of the catalyst) only a slight decrease (in the range of

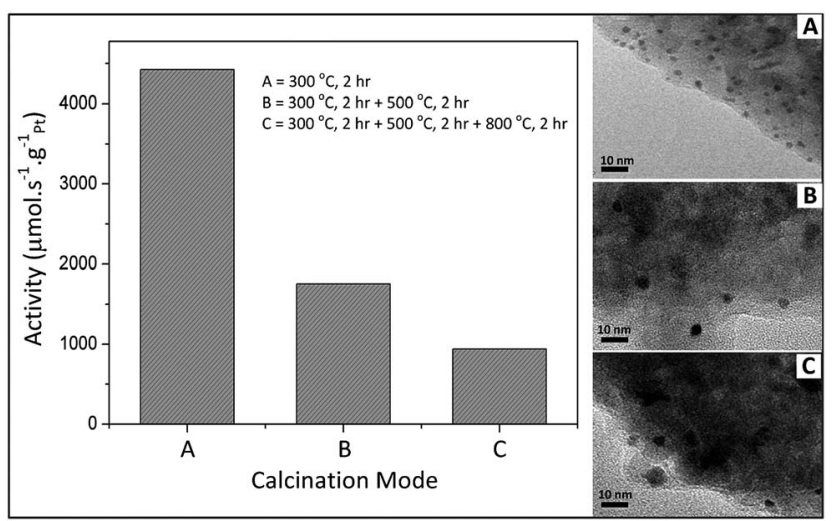

Fig. 7 The activities of the Pt catalysts prepared at different temperatures of calcinations and the corresponding TEM images. Each calcination temperature was held for $2 \mathrm{~h}$.
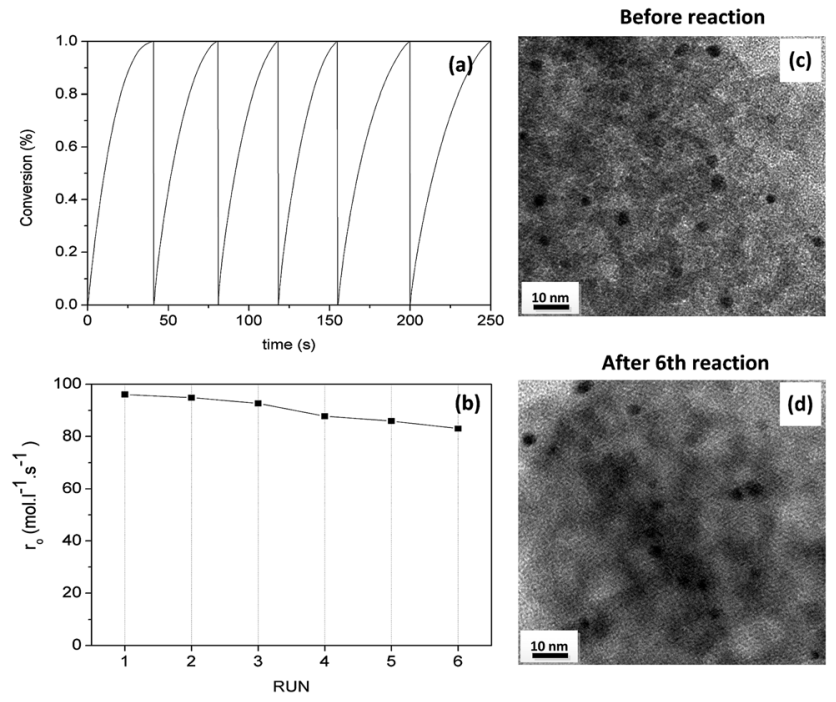

Fig. 8 Six hydrogenation runs of $1 \mathrm{~g}$ of AMS: (a) conversion $v$ s. time, (b) initial reaction rate of each hydrogenation run, and (c and d) TEM images of synthesized $0.1 \% \mathrm{Pt} @ \gamma-\mathrm{Al}_{2} \mathrm{O}_{3}$ before and after the hydrogenation reactions.

error) from the first run to the sixth run is observed; therefore, the catalyst is considered to be stable. This could lead to a conclusion that there is no significant change of the size and shape of the Pt catalyst during the reactions. The corresponding TEM pictures also confirm that there is no significant change in the size of platinum nanoparticles during the reactions. However, Fig. 7 indicates that the size and the shape of nanoparticles might change in higher temperature reactions. This could be anticipated by using mesoporous materials and hollow cages to provide restricted microenvironments for supporting the catalyst. We would conclude that a Pt catalyst supported on nonmesoporous $\mathrm{Al}_{2} \mathrm{O}_{3}$ is more suitable for reaction at low to the middle high temperature $\left(<300{ }^{\circ} \mathrm{C}\right)$.

\section{Conclusion}

We have demonstrated a new, simple yet excellent method to synthesize highly active and stable supported Pt catalysts via the so-called thermo-destabilization of microemulsions. In this study, we fixed the kind of surfactant (Triton X-100), cosurfactant (pentanol), solvent (cyclohexane), metal precursor $\left(\mathrm{H}_{2} \mathrm{PtCl}_{6}\right)$, and reducing agent (hydrazine). The parameters that significantly influence the activity of the produced catalysts are heating rate during the thermal destabilization process, molar ratio of water to surfactant $(\omega)$, initial molar ratio of metal to reducing agent, growing time, kinds of support material, and calcination temperature. The produced catalysts exhibit higher catalytic activities than those of conventional methods. We attribute this to the small size, multifaceted shape, narrow size distribution and good dispersion of the nanoparticles on surfaces of the support material. The insignificant difference of activity $(<1 \%)$ of the catalyst produced from different batches indicates that this method is reproducible. Comparative studies in applying our method to synthesize other supported metals such as $\mathrm{Ag}, \mathrm{Pd}$, and $\mathrm{Ru}$ on different kinds of material supports are still 
in progress to elucidate if the recipe can be generalized. We found that our method also works well with those metals, and we intend to publish these results later. Although we have found good results, we are still continuing to improve and optimize the performance of the catalyst.

\section{Acknowledgements}

The authors are grateful to the Ministry of National Education of Indonesia for financial support. Thanks to Patrick Littlewood for helping in writing this paper, Dipl. Sören Selve for performing the TEM/HRTEM measurements and to Astrid Müller for assisting with the ICP measurements. This work is also a part of the DFG funded Cluster of Excellence "Unifying Concepts in Catalysis".

\section{References}

1 R. Narayanan and M. A. El-Sayed, J. Phys. Chem. B, 2005, 109, $12663-12676$.

2 H. Gomes, P. Serp, P. Kalck, J. Figueiredo and J. Faria, Top. Catal., 2005, 33, 59-68.

3 A. E. Aksoylu, J. L. Faria, M. F. R. Pereira, J. L. Figueiredo, P. Serp, J.-C. Hierso, R. Feurer, Y. Kihn and P. Kalck, Appl. Catal., A, 2003, 243, 357-365.

4 M. Vlčko, Z. Cvengrošová and M. Hronec, Collect. Czech. Chem. Commun., 2008, 73, 1149-1160.

5 S. R. de Miguel, O. A. Scelza, M. C. Román-Martínez, C. SalinasMartínez de Lecea, D. Cazorla-Amorós and A. Linares-Solano, Appl. Catal., A, 1998, 170, 93-103.

6 N. Job, M. F. R. Pereira, S. Lambert, A. Cabiac, G. Delahay, J.-F. Colomer, J. Marien, J. L. Figueiredo and J.-P. Pirard, J. Catal., 2006, 240, 160-171.

7 H. Y. Kim, S. J. Lee and N. J. Jung, Solid State Phenom., 2007, 124126, 1769-1772.

8 I. Lee, F. Delbecq, R. Morales, M. A. Albiter and F. Zaera, Nat. Mater., 2009, 8, 132-138.

9 S. Eriksson, U. Nylén, S. Rojas and M. Boutonnet, Appl. Catal., A, 2004, 265, 207-219.

10 O. P. Yadav, A. Palmqvist, N. Cruise and K. Holmberg, Colloids Surf., $A, 2003,221,131-134$.

11 A. Pal, S. Shah, S. Belochapkine, D. Tanner, E. Magner and S. Devi, Colloids Surf., A, 2009, 337, 205-207.

12 L. M. Magno, D. G. Angelescu, W. Sigle and C. Stubenrauch, Phys. Chem. Chem. Phys., 2011, 13, 3048.

13 H. H. Ingelsten, J.-C. Beziat, K. Bergkvist, A. Palmqvist, M. Skoglundh, H. Qiuhong, L. K. L. Falk and K. Holmberg, Langmuir, 2002, 18, 1811-1818.

14 M. Yashima, L. K. L. Falk, A. E. C. Palmqvist and K. Holmberg, J. Colloid Interface Sci., 2003, 268, 348-356.

15 M. Ikeda, S. Takeshima, T. Tago, M. Kishida and K. Wakabayashi, Catal. Lett., 1999, 58, 195-197.

16 T. S. Ahmadi, Z. L. Wang, T. C. Green, A. Henglein and M. A. ElSayed, Science, 1996, 272, 1924-1925.

17 T. S. Ahmadi, Z. L. Wang, A. Henglein and M. A. El-Sayed, Chem. Mater., 1996, 8, 1161-1163.

18 J. Zhu, Z. Kónya, V. F. Puntes, I. Kiricsi, C. X. Miao, J. W. Ager, A. P. Alivisatos and G. A. Somorjai, Langmuir, 2003, 19, 4396-4401.

19 H. Song, R. M. Rioux, J. D. Hoefelmeyer, R. Komor, K. Niesz, M. Grass, P. Yang and G. A. Somorjai, J. Am. Chem. Soc., 2006, 128, 3027-3037.
20 C. Burda, X. Chen, R. Narayanan and M. A. El-Sayed, Chem. Rev., 2005, 105, 1025-1102.

21 D. H. M. Buchold and C. Feldmann, Adv. Funct. Mater., 2008, 18, $1002-1011$.

22 D. Zhao, Q. Huo, J. Feng, B. F. Chmelka and G. D. Stucky, J. Am. Chem. Soc., 1998, 120, 6024-6036.

23 J. S. Milano-Brusco, H. Nowothnick, M. Schwarze and R. Schomäcker, Ind. Eng. Chem. Res., 2010, 49, 1098-1104.

24 J. Eastoe, M. J. Hollamby and L. Hudson, Adv. Colloid Interface Sci., 2006, 128-130, 5-15.

25 A. K. Ganguli, A. Ganguly and S. Vaidya, Chem. Soc. Rev., 2010, 39, 474.

26 B. W. Müller and R. H. Müller, J. Pharm. Sci., 1984, 73, 919-922.

27 M. Lade, H. Mays, J. Schmidt, R. Willumeit and R. Schomäcker, Colloids Surf., A, 2000, 163, 3-15.

28 C.-K. Tsung, J. N. Kuhn, W. Huang, C. Aliaga, L.-I. Hung, G. A. Somorjai and P. Yang, J. Am. Chem. Soc., 2009, 131, 58165822 .

29 P. J. Ferreira and Y. Shao-Horn, Electrochem. Solid-State Lett., 2007, 10, B60-B63.

30 R. Swaminathan, M. A. Willard and M. E. McHenry, Acta Mater., 2006, 54, 807-816.

31 S. W. Lee, S. Chen, W. Sheng, N. Yabuuchi, Y.-T. Kim, T. Mitani, E. Vescovo and Y. Shao-Horn, J. Am. Chem. Soc., 2009, 131, $15669-15677$.

32 S. Alayoglu, C. Aliaga, C. Sprung and G. A. Somorjai, Catal. Lett., 2011, 141, 914-924.

33 M. Zhou, S. Chen, H. Ren, L. Wu and S. Zhao, Phys. E., 2005, 27, 341-350.

34 D. Adityawarman, A. Voigt, P. Veit and K. Sundmacher, Chem. Eng. Sci., 2005, 60, 3373-3381.

35 X. Zhang and K.-Y. Chan, Chem. Mater., 2003, 15, 451-459.

36 K. Niesz, M. Grass and G. A. Somorjai, Nano Lett., 2005, 5, 2238 2240.

37 Q. Shen, H. Wei, Y. Zhao, D.-J. Wang, L.-Q. Zheng and D.-F. Xu, Colloids Surf., A, 2004, 251, 87-91.

38 R. Ranjan, S. Vaidya, P. Thaplyal, M. Qamar, J. Ahmed and A. K. Ganguli, Langmuir, 2009, 25, 6469-6475.

39 D.-S. Bae, K.-S. Han and J. H. Adair, J. Am. Chem. Soc., 2002, 85, $1321-1323$.

40 A. R. Tao, S. Habas and P. Yang, Small, 2008, 4, 310-325.

41 S. Vaidya, P. Rastogi, S. Agarwal, S. K. Gupta, T. Ahmad, A. M. Antonelli, K. V. Ramanujachary, S. E. Lofland and A. K. Ganguli, J. Phys. Chem. C, 2008, 112, 12610-12615.

42 M. R. Rahman, F. S. Saleh, T. Okajima and T. Ohsaka, Langmuir, 2011, 27, 5126-5135.

43 S. Alayoglu, C. Aliaga, C. Sprung and G. A. Somorjai, Catal. Lett., 2011, 141, 914-924.

44 M. A. El-Sayed and J. W. Yoo, ChemCatChem, 2010, 2, 268-271.

45 Z. Liu, M. Shamsuzzoha, E. T. Ada, W. M. Reichert and D. E. Nikles, J. Power Sources, 2007, 164, 472-480.

46 R. M. Rioux, H. Song, M. Grass, S. Habas, K. Niesz, J. D. Hoefelmeyer, P. Yang and G. A. Somorjai, Top. Catal., 2006, 39, $167-174$

47 T. Teranishi, M. Hosoe, T. Tanaka and M. Miyake, J. Phys. Chem. B, 1999, 103, 3818-3827.

48 Z. L. Wang, J. M. Petroski, T. C. Green and M. A. El-Sayed, J. Phys. Chem. B, 1998, 102, 6145-6151.

49 M. Boutonnet, J. Kizling, R. Touroude, G. Maire and P. Stenius, Catal. Lett., 1991, 9, 347-354.

50 E. Romero-Pascual, A. Larrea, A. Monzón and R. D. González, J. Solid State Chem., 2002, 168, 343-353.

51 J. T. Miller, M. Schreier, A. J. Kropf and J. R. Regalbuto, J. Catal., 2004, 225, 203-212. 